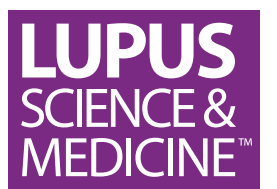
Cherif $\mathrm{Y}$, et al. Causes and outcome of hospitalisations in Tunisian patients with systemic lupus erythematosus. Lupus Science \& Medicine 2014;1: e000017. doi:10.1136/lupus2014-000017

Received 26 January 2014 Revised 22 April 2014 Accepted 8 May 2014
CrossMark

\footnotetext{
${ }^{1}$ Department of Internal

Medicine, Hedi Chaker

University Hospital, Sfax,

Tunisia

2Department of Immunology, Habib Bourguiba University Hospital, Sfax, Tunisia

Correspondence to Dr Moez Jallouli; jallouli5moez@yahoo.fr
}

\title{
Causes and outcome of hospitalisations in Tunisian patients with systemic lupus erythematosus
}

\author{
M Jallouli, ${ }^{1} \mathrm{H}$ Hriz, ${ }^{1}$ Y Cherif, ${ }^{1}$ S Marzouk, ${ }^{1}$ M Snoussi, ${ }^{1}$ F Frikha, ${ }^{1}$ R Ben Salah, ${ }^{1}$ \\ $\mathrm{H}$ Masmoudi, $^{2}$ Z Bahloul ${ }^{1}$
}

\section{ABSTRACT}

Objective: To describe the most common reasons of admission of Tunisian patients with systemic lupus erythematosus (SLE) and the outcomes of these hospitalisations.

Method: The charts of patients with SLE who were hospitalised at our Department of Internal Medicine during a 2-year period from January 2011 to December 2012 were retrospectively reviewed, and the demographic characteristics, clinical and laboratory features, as well as all comorbidities, were collected.

Results: There were 128 episodes of hospitalisation of 87 patients with SLE. 25 patients $(28.7 \%)$ were admitted twice or more. The median length of stay for all admissions was 11 days (2-76). The total number of days of hospitalisation was 1896 days, which represent $10.7 \%$ of the total number of days of hospitalisation in our department. The most common overall reason for hospitalisation was active SLE (55 events, 43\%). In 29 patients, SLE was newly diagnosed during hospitalisation. Other causes of hospitalisation included assessment of the disease, infections (9.4\%) and associated autoimmune disease $(6.25 \%)$. Adverse drug reaction (3.1\%) and thromboembolic events $(1.25 \%)$ were uncommon causes of hospitalisations. There was a significant difference in length of stay between patients admitted with SLE flare and those admitted for non-SLE flare reasons $(p<0.01)$. Four hospitalisations $(3 \%)$ resulted in death. The principal cause of death was active SLE. Conclusions: Hospitalisation of patients with SLE is common in our department. Our study of this North African SLE population confirms the findings of previous studies suggesting that active SLE and infection remain the most common causes of hospitalisation of patients with SLE.

\section{INTRODUCTION}

Systemic lupus erythematosus (SLE) is an autoimmune disease of unknown aetiology with a broad spectrum of clinical and immunological manifestations. This chronic disease is difficult to diagnose and treat, and patients with SLE may require frequent hospitalisations. Few studies on hospitalisation of patients with SLE have been reported earlier. $^{1-6}$ These studies have involved North Americans, ${ }^{2}{ }^{3}$ Asians $^{1}$ but not North Africans.

The objective of this study was to describe the most common reasons of admission and the outcomes of patients with SLE in Tunisia.

\section{PATIENTS AND METHODS}

We retrospectively reviewed the charts of patients with SLE who were hospitalised at the Department of Internal Medicine at the Hédi Chaker University Hospital, Sfax, Tunisia, during a 2-year period from January 2011 to December 2012. This is a tertiary referral centre for the treatment of patients with SLE, and most of our patients come from across southern Tunisia. All patients fulfilled four or more criteria for the diagnosis of SLE as defined by the American College of Rheumatology.

Data on demographic characteristics, clinical and laboratory features, as well as all comorbidities, were collected and recorded on standard forms.

We consider only the primary cause for hospitalisation as the reason for admission.

\section{STATISTICAL ANALYSIS}

Standard $\chi^{2}$ and Fisher's exact tests were used to analyse qualitative differences, and Student $\mathrm{t}$ test to compare the means in large independent samples of similar variance. A $p$ value $<0.05$ was defined as statistically significant. The statistical analysis was performed with SPSS/PC V.13.0 software.

\section{RESULTS}

During the study, 87 patients with SLE who were admitted at least once in our department. Among these, 80 (92\%) were female and $7(8 \%)$ male. The mean age was 31.5 
\pm 11.5 years at diagnosis and $35.3 \pm 12.8$ years at admission. The median disease duration between diagnosis and hospitalisation was 26 months (0-288 months).

During this study, there were 128 hospitalisation events, which represent $5.95 \%$ of all admissions in our department. Twenty-five patients $(28.7 \%)$ were admitted twice or more.

Table 1 lists all the discharge diagnoses in patients with SLE. The most common overall reason for hospitalisation was active SLE ( 55 events, 43\%). In 29 patients, SLE was newly diagnosed during hospitalisation. The other 26 patients experienced a flare after a median time of 42 months (2-140). Patients hospitalised for SLE

Table 1 Causes of hospitalisations.

\begin{tabular}{ll}
\hline & $\begin{array}{l}\text { Number of } \\
\text { patients } \\
\text { (percentage) }\end{array}$ \\
Reason for hospitalisation & $55(43)$ \\
\hline Active SLE & $29(22.6)$ \\
Newly diagnosed SLE & $26(20.3)$ \\
Known SLE & \\
Types of flare (n) & \\
Haematological (31) & \\
Mucocutaneous (22) & \\
Articular (18) & \\
Renal (17) & \\
Serositis (9) & \\
Neuropsychiatric (3) & \\
Assessment of the disease & \\
Infection & \\
Pneumonia (5) & \\
Bacterial arthritis (salmonella) (2) & \\
Urinary tract infection (2) & \\
Cellulitis (2) & \\
Brucellosis (1) & \\
Associated autoimmune diseases & \\
Inflammatory myositis (4) & \\
Autoimmune thyroiditis (1) & \\
Systemic sclerosis (1) & \\
Pernicious anaemia (1) & \\
Autoimmune hepatitis (1) & \\
Adverse drug reaction & \\
Anticoagulant related bleeding (2) \\
Hydroxychloroquine induced
\end{tabular}

disease flare compared with other causes were younger (32 vs 37.8 years; $\mathrm{p}<0.001$ ) and had a shorter disease course (42 (2-140) vs 57 (1-288) months; p=0.04). Among the individuals admitted with active disease, cutaneous and haematological manifestations were the most common (table 1). Seventeen patients (30.9\%) had active lupus nephritis.

Acute infections were responsible for $9.4 \%$ of admissions. The majority of infections was bacterial and included pulmonary (five cases), urinary tract (two cases) and cutaneous (two cases) infections. There were two cases of salmonella arthritis and one case of brucellosis.

The diagnosis of an associated autoimmune disease accounted for $6.25 \%$ of admissions. They included inflammatory myositis (four cases), autoimmune thyroiditis (one case), systemic sclerosis (one case), autoimmune hepatitis (one case) and pernicious anaemia (one case). Adverse drug reaction $(3.1 \%)$ and thromboembolic events $(1.25 \%)$ were uncommon causes of hospitalisations.

The median length of stay for all admissions was 11 days with a range from 2 to 76 days. The total number of days of hospitalisation of patients with SLE was 1896 days, which represent $10.7 \%$ of the total number of days of hospitalisation in our department. There was a significant difference in length of stay between patients admitted with SLE flare and those admitted for non-SLE flare reasons $(18(2-70)$ vs 8 (276) days; $\mathrm{p}<0.01$ ).

Among 128 hospitalisations, 4 (3\%) resulted in death (table 2). All patients were initially hospitalised for severe active SLE. During their hospitalisation, one patient had also pneumonia and the other a perirenal haematoma secondary to a renal biopsy.

\section{DISCUSSION}

In this retrospective series, we describe the most common reasons of admission and the outcomes of

Table 2 Characteristics of patients who died during hospitalisation.

\begin{tabular}{|c|c|c|c|c|}
\hline Patient & Age & Sex & $\begin{array}{l}\text { Years since } \\
\text { diagnosis }\end{array}$ & Cause of death \\
\hline 1 & 42 & $\mathrm{~F}$ & 0 & $\begin{array}{l}\text { Active SLE with } \\
\text { severe renal disease, } \\
\text { APLS, haemorrhage } \\
\text { from perirenal } \\
\text { haematoma }\end{array}$ \\
\hline 2 & 25 & $F$ & 10 & $\begin{array}{l}\text { Active SLE with } \\
\text { severe renal disease }\end{array}$ \\
\hline 3 & 36 & $F$ & 2 & $\begin{array}{l}\text { Active SLE with } \\
\text { severe renal disease, } \\
\text { MAS, pneumonia }\end{array}$ \\
\hline 4 & 24 & $F$ & 0 & $\begin{array}{l}\text { Active SLE with } \\
\text { severe encephalitis }\end{array}$ \\
\hline
\end{tabular}

APLS, Antiphospholipid syndrome; MAS, Macrophage activation syndrome; SLE, systemic lupus erythematosus. 
patients with SLE in Tunisia. Few studies on hospitalisation of patients with SLE have been reported earlier. ${ }^{1-6}$ These studies have involved North Americans, ${ }^{2} 3$ Asians ${ }^{1}$ but not North Africans.

We found that SLE was responsible for $5.95 \%$ of all admissions in our department. These findings point out that although SLE is a rare condition, the number of patients with SLE is not trivial. Patients with SLE had also a high healthcare use $^{8}$ since they were responsible for $10.7 \%$ of the total number of days of hospitalisation.

In our study, active SLE was the most common reason for hospitalisation of patients with SLE (43\%). This is consistent with the results reported in the literature. ${ }^{1-3}$ The rate of admissions for this cause is higher than that reported in Northern America (17.5-35\%) ${ }^{2}{ }^{3}$ but lower when compared with Asian populations (58\%). ${ }^{1}$ These discrepancies may be due to ethnic and socioeconomic characteristics and to differences in healthcare systems. The patients hospitalised for SLE disease flare compared with other causes had a shorter disease course, like other series. ${ }^{3} 8$ These findings are expected since it is well known that SLE is mainly active in the first 5 years of disease progression.

The second most common reason for hospitalisation of our patients with SLE was disease's assessment $(26.5 \%)$. Our department is a tertiary referral centre for the treatment of patients with SLE and most of our patients come from across southern Tunisia. Thereby, this high rate might be explained by a strategy of our medical team to overcome difficulties of healthcare access as many of our patients live in remote areas.

Despite the great improvement in the management of SLE, infection remains an important cause of morbidity and mortality in patients with SLE. As seen in literature, ${ }^{1-3} 9$ acute infections were one of the leading causes of hospitalisations in our study and accounted for $9.4 \%$ of admissions.

It is common that SLE aggregates with other autoimmune diseases. The study of Chambers $e t a l^{10}$ suggests that up to a third of lupus patients might develop another autoimmune disease and that the prevalence of some of them (Sjogren's syndrome, Hashimoto's hypothyroidism, myositis, antiphospholipid syndrome, etc) could be higher than in the general population. The present study emphasises that there is a high prevalence of polyautoimmunity in patients with SLE since it represents the fourth most common reason for hospitalisation of patients with SLE $(6.25 \%)$.

Interestingly, there was no hospitalisation due to coronary artery disease during our study. In an earlier report, ${ }^{11}$ we found that no patient died of cardiovascular event. While coronary artery disease is firmly established as a major cause of mortality and morbidity in other ethnic groups, ${ }^{6} 1213$ it remains a less frequent cause of hospitalisation in our population. These findings are comparable to those seen in Chinese $^{1}$ and South Koreans. $^{14}$

In conclusion, hospitalisation of patients with SLE is common in our department and can be prolonged. Our study of this North African SLE population confirms the findings of previous studies suggesting that active SLE and infection remain the most common causes of hospitalisation of patients with SLE.

\section{Competing interests None.}

Provenance and peer review Not commissioned; externally peer reviewed.

Data sharing statement No additional data are available

Open Access This is an Open Access article distributed in accordance with the Creative Commons Attribution Non Commercial (CC BY-NC 3.0) license, which permits others to distribute, remix, adapt, build upon this work noncommercially, and license their derivative works on different terms, provided the original work is properly cited and the use is non-commercial. See: http:// creativecommons.org/licenses/by-nc/3.0/

\section{REFERENCES}

1. Edwards CJ, Lian TY, Badsha $\mathrm{H}$, et al. Hospitalization of individuals with systemic lupus erythematosus: characteristics and predictors of outcome. Lupus 2003;12:672-6.

2. Lee J, Dhillon N, Pope J. All-cause hospitalizations in systemic lupus erythematosus from a large Canadian referral centre. Rheumatology (Oxford) 2013;52:905-9.

3. Petri M, Genovese M. Incidence of and risk factors for hospitalizations in systemic lupus erythematosus: a prospective study of the Hopkins Lupus Cohort. J Rheumatol 1992;19:1559-65.

4. Lee J, Peschken C, Muangchan C, et al. The frequency of and associations with hospitalization secondary to lupus flares from the 1000 Faces of Lupus Canadian cohort. Lupus 2013;22:1341-8.

5. Krishnan E. Hospitalization and mortality of patients with systemic lupus erythematosus. J Rheumatol 2006;33:1770-4.

6. Karrar A, Sequeira W, Block JA. Coronary artery disease in systemic lupus erythematosus: A review of the literature. Semin Arthritis Rheum 2001;30:436-43.

7. Hochberg MC. Updating the American College of Rheumatology revised criteria for the classification of systemic lupus erythematosus. Arthritis Rheum 1997;40:1725

8. Zhu TY, Tam LS, Lee VW, et al. The impact of flare on disease costs of patients with systemic lupus erythematosus. Arthritis Rheum 2009;61:1159-67.

9. Goldblatt F, Chambers S, Rahman A, et al. Serious infections in British patients with systemic lupus erythematosus: hospitalisations and mortality. Lupus 2009;18:682-9.

10. Chambers SA, Charman SC, Rahman A, et al. Development of additional autoimmune diseases in a multiethnic cohort of patients with systemic lupus erythematosus with reference to damage and mortality. Ann Rheum Dis 2007;66:1173-7.

11. Jallouli $M$, Frigui $M$, Hmida $M B$, et al. Clinical and immunological manifestations of systemic lupus erythematosus: study on 146 south Tunisian patients. Saudi J Kidney Dis Transp/ 2008;19:1001-8.

12. Esdaile JM, Abrahamowicz M, Grodzicky T, et al. Traditional Framingham risk factors fail to fully account for accelerated atherosclerosis in systemic lupus erythematosus. Arthritis Rheum 2001;44:2331-7.

13. Manzi S, Meilahn EN, Rairie JE, et al. Age-specific incidence rates of myocardial infarction and angina in women with systemic lupus erythematosus: comparison with the Framingham Study. $\mathrm{Am} \mathrm{J}$ Epidemiol 1997;145:408-15.

14. Chun BC, Bae SC. Mortality and cancer incidence in Korean patients with systemic lupus erythematosus: results from the Hanyang lupus cohort in Seoul, Korea. Lupus 2005;14:635-8. 